\title{
Ultimate Limit State Analysis of Ship Structures
}

\author{
S. Sathish Kumar, B.E. Naval Architecture, AMRINA \\ Oman Drydock Company LLC \\ Al Duqum, Oman \\ sathishkumar11189@gmail.com
}

\section{Synopsis}

Subjective and objective uncertainties are imposed on ship structures due to the random nature of the loading environment, inadequate knowledge of physical phenomena associated with loads or deviations in material properties which make reliable predictions of structural response a difficult task. Strength criteria for ships can be established by ultimate strength studies of progressive collapse analysis of finite element models under different boundary conditions with combined geometric and material nonlinearities. Load-Displacement and/or Moment-Curvature curves can be generated and the ultimate load causing failure identified as a multiple of the design load. Ultimate limit state analysis can be carried out for various combinations of parameters to identify the ultimate load factor in each case.

Keywords - Ship Structure, Finite Element Analysis, Ultimate Strength Analysis, Nonlinear Static Analysis, Geometric and Material Nonlinearity.

\section{Introduction}

The era of structural design of ships based on 'accumulated experience' or semi empirical formulae is already over. Structural design of ships based on Ultimate Limit State (ULS) using computer aided analysis has come into practice with the blessings of classification societies, especially with the formation of International Association of Classification Societies (IACS). The ship structural design philosophy has gone through substantial change in the last thirty years with the incorporation of concepts in ultimate strength.
The hull module being a three dimensional structural entity comprised of stiffened plates, its ultimate strength has always been associated with large deformation and inelastic buckling of plates. Hughes [4] identified the longitudinal and transverse collapse of hull modules and has suggested a procedure for the ultimate strength analyses. The limit state design concept has wider scope than the rule based or working stress design approaches, since it incorporates probabilistic basis for failure from both the functional and operational aspects.

Limit states in the ship structural design have been identified as serviceability, ultimate, fatigue and accidental limit states represented in short as SLS, ULS, FLS and ALS respectively. Each of the limit states are assigned with a safety margin which is a function of perceived consequences and ease of recovery from that state to be incorporated in strength amendment. ULS is normally identified with a maximum or near maximum action effects which may result in local or global failure.

\section{Ship Structures}

\subsection{Studies on Ship Structures}

The sources of uncertainty of ship structural analysis are the assumptions made in the formulations and models for the analysis (like Bernoulli' assumption) in simple bending when adopted for the primary bending analysis of hull girder, love Kirchhoff's assumptions on small deflection plate theory for the analysis of 'plates' in ship structure, effective width consideration in grillage analysis and the geometric factors like initial imperfections etc. The ship structural design parameters like yield strength, fracture toughness, residual stress, thickness and initial imperfections contribute to objective uncertainties and statistical parameters may be derived from the collated data. 
Uncertainties in the form of operating errors or change in service conditions are also present. Structural safety is quantified by the margin between applied load and the load carrying capacity of the structure, and is expressed as structural safety function.

\subsection{Ultimate Strength of ship structures}

The ultimate strength of the hull is defined as the maximum load that the structure can withstand at any section before collapse. Hull girder ultimate strength is identified as the most crucial structural design parameter for most warships and large commercial vessels. It depends on a number of factors including the strength of the structural material, the dimensions and layout of the structural elements and the tendency for local structure to buckle under compressive loading.

Ultimate strength can change throughout a vessel's service life as a result of structural modifications during refit and in-service damage, so it is necessary to evaluate ultimate strength at various stages of service life, not just at the design stage. Various means have been developed for evaluating the ultimate strength. The simplest form is the empirical formulae based on the analysis of idealized box girders. The most complex method is three dimensional nonlinear finite element analysis of the hull girder. In between these two extremes, specialized methods that retain some of the simplifying assumptions of the analytical methods as well as the accuracy of nonlinear finite element methods have also been developed. One such method is the Independent Structural Unit Method (ISUM).

Another is the Progressive Failure method originally developed by Smith. The stiffened panels of the hull are normally sufficiently strong such that the mode of compressive collapse is not elastic panel buckling but falls in the inelastic regime. The hull being a 3D structural identity composed of plates and stiffeners, its collapse involves combination of plate deformation and inelastic buckling. Hence an investigation on ultimate strength is a necessity for the hull. It has been discussed elsewhere and established that there are only two independent models of overall collapse for the hull module, viz., the longitudinal collapse and the transverse collapse.
Also that longitudinal collapse will occur only between two adjacent frames. Hull module of a ship is essentially a thin walled box structure. Since all thin walled structures are susceptible to issues arising from buckling and large deformations, the need for nonlinear analysis is paramount. Failure of ship structures is typically related to either geometric nonlinearity or material nonlinearity. The source of geometric nonlinearity can be attributed to large deflections and large strains, which are common in thin walled structures. Shipbuilding steels definitely have a nonlinear stress strain pattern. To sum it up, the necessity for geometric and material nonlinear analysis of the hull module is imperative for ultimate strength prediction.

The use of ultimate limit state design methods in the maritime industry is increasing. Recent developments in this area include the Common Structural Rules (CSR) by International Association of Classification Societies and ULS assessment by International Organization for Standardization (ISO). The IACS CSR methods have been regularly applied in the design and strength assessment of ships and offshore structures, and the ISO 18072 standard has been in effect since November 2007.

Finite element analysis is universally recognized as the most important technological breakthrough in the field of engineering analysis of structures. The development of computing capabilities has caused the finite element method to become one of the most popular techniques for solving engineering problems. For analyzing a complicated structure like a ship hull, the finite element method is the only tool which is giving satisfactory results.

\section{Models of Ship for Limit State Analysis}

Hull structure of ships consists of a steel framework surrounded by steel plating. A hull girder is a three- dimensional framework of beams and stiffened panels. On a hull girder, most of the lateral loads act initially on the plating. Then, through the action of plate bending, the plating transmits the load to the nearby major beams, the transverse frame and longitudinal girders. The identification of the critical segment is the hull module and rigorous analysis procedures for the determination of the ultimate strength are the crucial steps in this. 
When ship structural analysis is carried out using substructures, the results strongly depend on the boundary conditions of the model taken. The more local the model, the stronger is this dependency. The extent of action effect analysis for each model must be large enough so that the structural area of interest will be relatively unaffected by approximations in the boundary conditions. The structural models used for finite element analysis of ships are global structure model, hull module (hold model), grillage model, frame model and local structure model. These models are described in the subsequent section.

\subsection{Global Strcutural Model}

The global structure model is used to investigate the action effects of the overall ship hull and its primary strength members to both still water and wave-induced hull girder actions. At this level the primary concern is the overall stiffness and the 'global' or 'nominal' stresses of primary strength components along the entire ship length, rather than local or detailed stresses.

The finite element analysis model is usually the full length of the ship. Half symmetry will normally be made use of and that reduces the computational cost and effort. All longitudinal members and all primary transverse members, (e.g., bulkheads, cross decks, transverse webs) which contribute to strength are included in the finite element analysis model. A coarse mesh extending over the entire ship hull length is usually adopted.

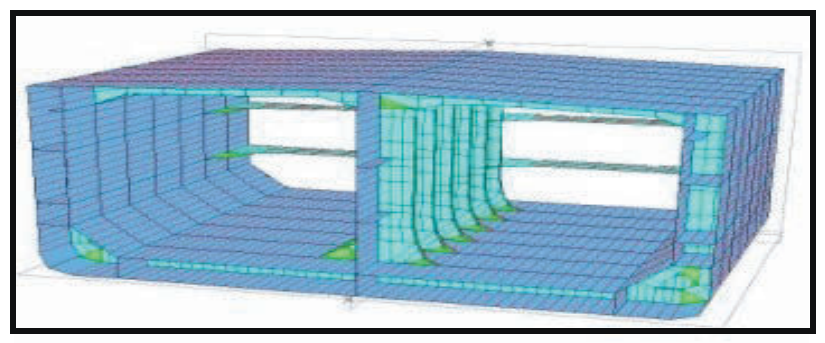

Figure 1: Global Structure model

\subsection{Hold Model}

The hold model is used to examine the response of the primary strength components in a particular portion of the hull girder under the action of internal cargo and external water pressure.

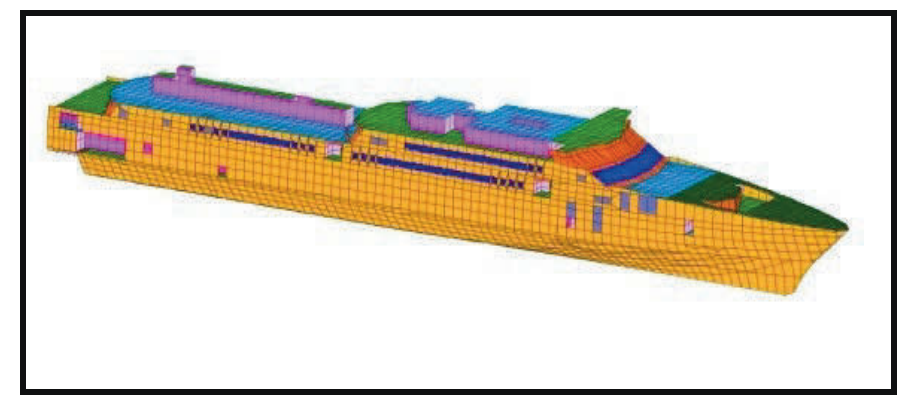

Figure 2: Hold model

The extent of the cargo hold considered to constitute the finite element model for analysis depends on the ship type, the loading conditions and the degree of symmetry of the hull structure in the longitudinal and transverse directions. A single hold, two cargo hold lengths (i.e., $1 / 2+1+1 / 2$ ) or three hold lengths (i.e., $1+1+1$ ) may be used [8]. A half breadth model may be used only if the available finite element program being used can correctly model unsymmetric actions effectively. The finite element hold model is usually made with a coarse mesh

\subsection{Frame Model}

The frame model is related to the action effects of two or three dimensional frame structures such as transverse web frame systems or longitudinal girder systems, including the flanges that are provided by the associated plating. The purpose of these frame analyses is to examine the bending and shear behaviour in the plane of the structure web, and also torsion, for which fine mesh modelling is required. Plate-shell element is typically used to model plating between stiffeners.

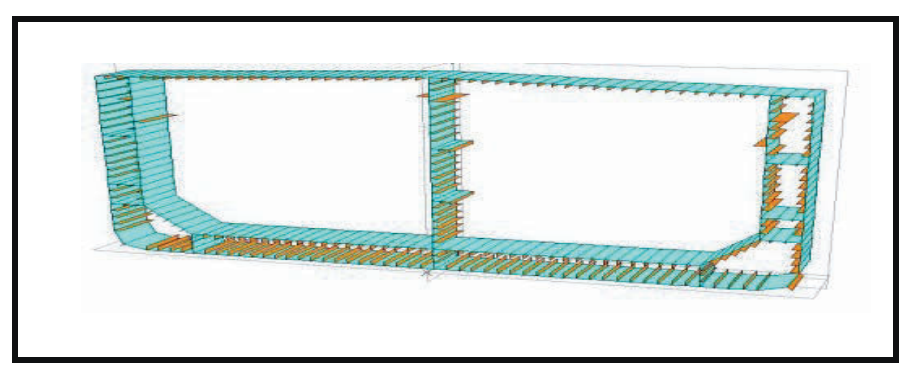

Figure 3: Frame model

\subsection{Local Stuctural Model}

The local structure model is used to investigate the action effects of local or special structural components, and of structural details. 
An example of a local member is a laterally loaded plate stiffener with its connecting brackets, subject to relative deformations between end supports. A fine meshing which provides a good aspect ratio of the plate-shell elements is generally required to reflect the behaviour of the local structure under large deformations.

\section{Boundary Condition}

Kinematic boundary conditions are incorporated by suppressing or prescribing translational displacements and/or rotations at the relevant nodes to represent the interaction between structural neighborhoods along the boundaries, or to represent the constraints at existing supports. For the global level analysis, sufficient degrees of freedom are constrained to prevent the rigid body motion of the model. The translational supports should be located away from the areas where the stresses are of interest. For lower level analyses, symmetric boundary conditions can be applied considering the symmetry related to structural arrangements and load application.

Also, the boundary conditions may be prescribed based on the load effects obtained from a higher level. The (translational or rotational) displacements or forces may be applied at the boundaries of the model. When the half breadth model is used, symmetric conditions are generally applied with regard to the centre line. If the model is subjected to uniform lateral loads alone, symmetric conditions can also be applied with reasonable certainty even at the ends, and the additional stresses due to global hull girder bending may be superimposed on the results. On the other hand, if hull girder bending and shearing forces are applied, distributed displacements or forces which can be obtained from the results of the global structure analysis may be prescribed over the cross section at the ends. Alternatively, it may be considered that the hull module is supported in the vertical direction by vertical springs along the intersections of the side and the transverse bulkhead, between the internal decks/structures and the transverse bulkhead, and between the longitudinal bulkhead and the transverse bulkhead. The spring constants are uniformly distributed along the corresponding intersections.
Instead of application of the vertical springs, vertical forces may be applied along the intersections mentioned above, but the displacement of one nodal point at each intersection is additionally fixed in the vertical direction to remove the rigid body motion. The boundary conditions for the hull module under hull girder loads are different from those under local loads. For hull girder vertical bending, it is often modelled that a simple support condition at transverse bulkhead locations of the hull module is often taken. For vertical shearing forces, the symmetric boundary conditions are generally applied at both ends of the cargo hold model. When only a half breadth of the ship is taken and under vertical shearing forces, symmetric boundary conditions are also applied along the centre line.

\section{Structural Loads for Ultimate Limit State Analysis}

The seaway loads on a hull have been classified as global loads which act on the hull girder and local loads which have a localized effect and act only on certain parts of it. Depending on the time domain description, loads can further be classified as static and dynamic and this classification is valid for each of the local and global categories. The general global loads acting on the hull comprises of bending moments arising from still water loads and thermal loads. Low frequency wave induced loads like vertical and horizontal bending and torsional moments and high frequency springing and slamming loads are also treated as global loads. Major constituents of the local loads are external static still water loads, external hydrodynamic pressure due to waves, cargo inertial loads due to vessel accelerations and internal liquid sloshing loads.

Fatigue is fast emerging as a failure mode of ship structures and therefore needs special consideration in the ship structural design. Wave loads which are the major seaway loads are random in nature and hence probabilistic representations are critical for them. Procedures of extrapolation of these loads to their extreme lifetime values are being exercised. Generally, these loads are dynamic and random and their combinations require the difficult but important analyses for determining the degree of correlation between the individual components. 
These analyses may be carried out either in a frequency domain or time domain. In the ship structural design practice, both hydrostatic and self-weight loads can be determined for a given ship condition with a high degree of confidence. The underwater shape of the hull is readily determined from detailed knowledge of the hull offsets and appendages, enabling the buoyancy distribution to be calculated. While buoyancy distribution is known from an early stage of the ship design, accurate weight distribution is defined only at the end of construction. Statistical formulations calibrated on similar ships can be used in the design development to provide an approximate quantification of weight items and their longitudinal distribution on board.

The resulting approximated weight distribution, together with the buoyancy distribution, allows computation of shear and bending moment in the still water condition by successive integration. This bending moment is always referred as the Still Water Bending Moment (SWBM).

The evaluation of wave generated hydrodynamic loads, however, is less reliable and there is less guidance as to how to handle the dynamic nature of the loading as well as transient effects such as slamming and sloshing. Nonlinear theories and three-dimensional load prediction methods have been introduced but these require greater computational effort and have not yet proven to be significantly more accurate than the two dimensional methods, regarding the design considerations.

For the global structure level analysis, various conditions of standard hull girder actions (e.g., vertical still water bending, vertical waveinduced bending, horizontal bending, wave induced torsion) and their combinations are to be considered in compliance with the guidelines or requirements specified by classification societies. The magnitude of pressure actions on the transverse bulkheads are calculated for the worst cases.A set of the sectional forces and moments are selected from those obtained for various load application, operating conditions and sea states, which give maximum hogging and sagging moments in the cargo hold area and maximum shearing forces at the bulkhead locations.

\section{Significance of Combined Non-linear Analysis of Ship Structure}

Hull module of the ship being a box structure constituted with stiffened panels, it falls in the category of thin walled box structures, open or closed depending on the type of the ship. This warrants the need for nonlinear analysis. In general, the two categories of nonlinear analysis, viz., geometric nonlinear analysis and the material nonlinear analysis have applications in ship structural analysis. The source of geometric nonlinearity can be attributed to large deflections and large strains, which are common in thin walled structures. Since shipbuilding steels have a nonlinear stress strain pattern beyond the yield point, the necessity for geometric and material nonlinear analysis of the hull module is imperative.

When the displacements and rotations become large requiring the equilibrium equations to be written for the deformed configuration rather than the initial one or part of the structure looses stiffness because of buckling, it is called geometric nonlinearity. When elastic material becomes plastic or material does not have linear stress strain relationship at any stress level, it is called material nonlinearity. When the loads do not maintain their original directions, it is environmental loading nonlinearity.

The scope of the nonlinear structural analysis is spread over buckling analysis, ultimate strength analysis and analysis of accidental or extreme situations like explosions, collisions, grounding, blast etc.,. These are very useful to understand possible failure modes and mechanical behaviour under severe loads.

The material nonlinear analysis predicts plasticity behaviour of the structure. The yield criterion relates the onset of yielding to the state of stress. For shipbuilding steel, the von Mises criterion is commonly used. The hardening rule describes how the yield surface grows and moves as plastic strains accumulate. Metals including steel can be described using the kinematic hardening. In this case, when the von Mises stress reaches yield stress, yielding can be assumed to have begun. The flow rule relates stress increments, strain increments and the state of stress in the plastic range. 
Geometric stiffness matrix which is derived based on the nonlinear terms in the stress displacement relations are used along with linear elastic stiffness matrix for the geometric nonlinear analysis. The material nonlinearity is incorporated by means of constitutive matrix which already carries nonlinear terms. These matrices will be modified in the iterative procedure at every load step.

\section{Estimation of Ultimate Limit State Parameters}

The primary step in predicting the ultimate strength parameters of a ship is the choice of the model. Modelling the full ship structure is a difficult and time consuming process. Generally the most critical hold model can be used under various possible boundary conditions. Progressive collapse analysis under combined geometric and material nonlinearities can be carried out for these conditions to analyse the collapse pattern and to identify the Ultimate Load Factor as the ratio of the collapse load to the design load. The Moment-Curvature $(\mathrm{M}-\varphi)$ or the load-displacement (P- $\Delta$ ) curves indicating the Ultimate Load Factor can be plotted for each case.

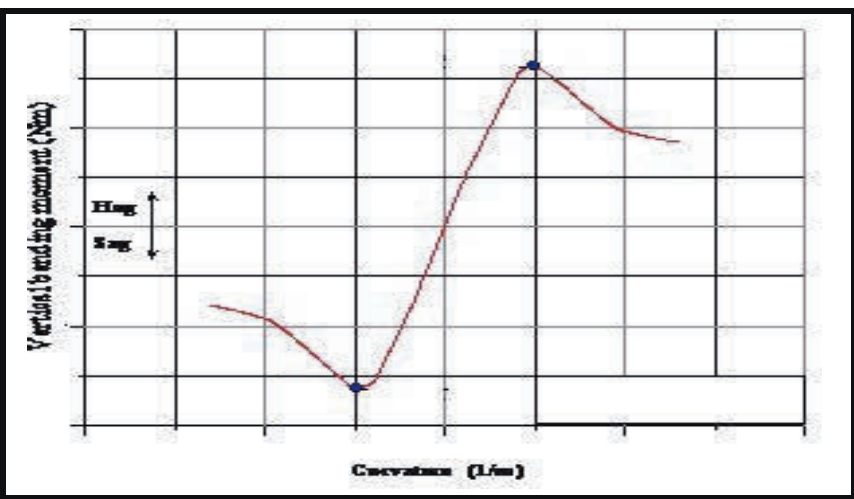

Figure 4: Typical Moment-Curvature Curve

\subsection{Ultimate Limit State Analysis of a Long, Slender Ship}

Structural scantlings of a long, slender ship with $132 \mathrm{~m}$ length and $9 \mathrm{~m}$ depth, designed in accordance with the provisions for structural design of ships published by the Lloyds Register of Shipping was analyzed for Ultimate Strength. The ship has three decks, spaced $2.4 \mathrm{~m}$ apart between the main deck and the inner bottom.

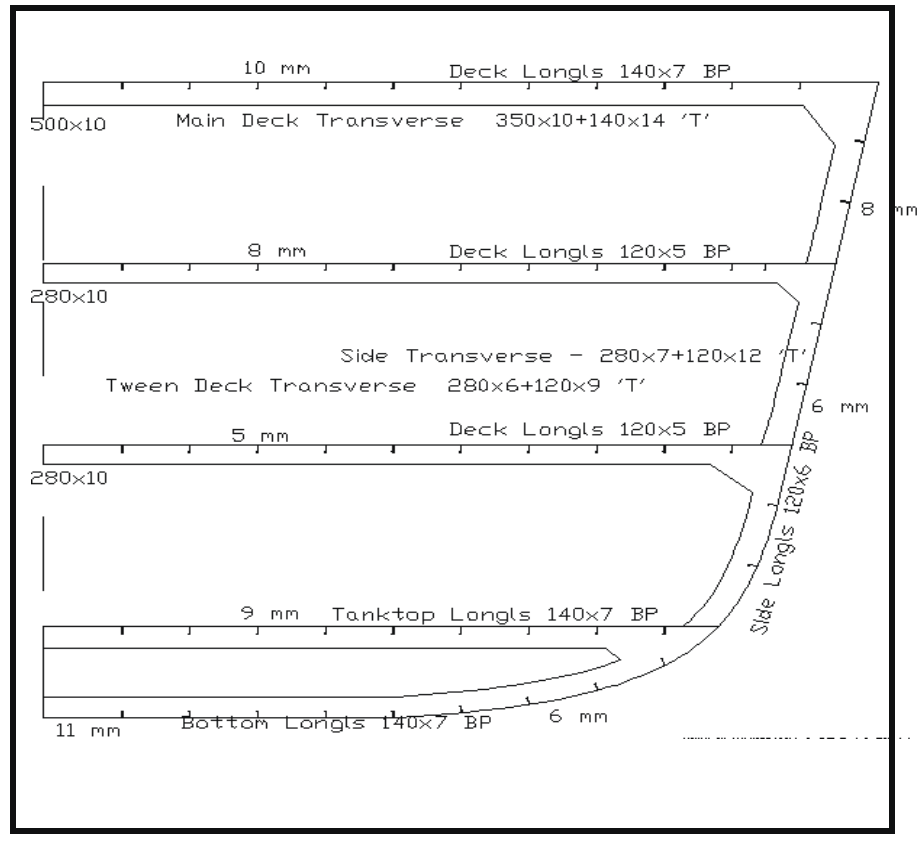

Figure 5 : Midship Section of the Hull Girder

Material of construction has been chosen as high strength ship building steel with yield stress $\sigma \mathrm{Y}$ of $390 \mathrm{MPa}$ and ultimate stress $\sigma \mathrm{U}$ of $590 \mathrm{MPa}$. Transverse stiffeners were spaced at $1500 \mathrm{~mm}$, and longitudinal stiffeners at $800 \mathrm{~mm}$. Double bottom height were $1200 \mathrm{~mm}$. The structural configuration of the midship section is shown in figure 5

The longest compartment of the ship is selected as the hold model. The FE model is indicated in figure 6

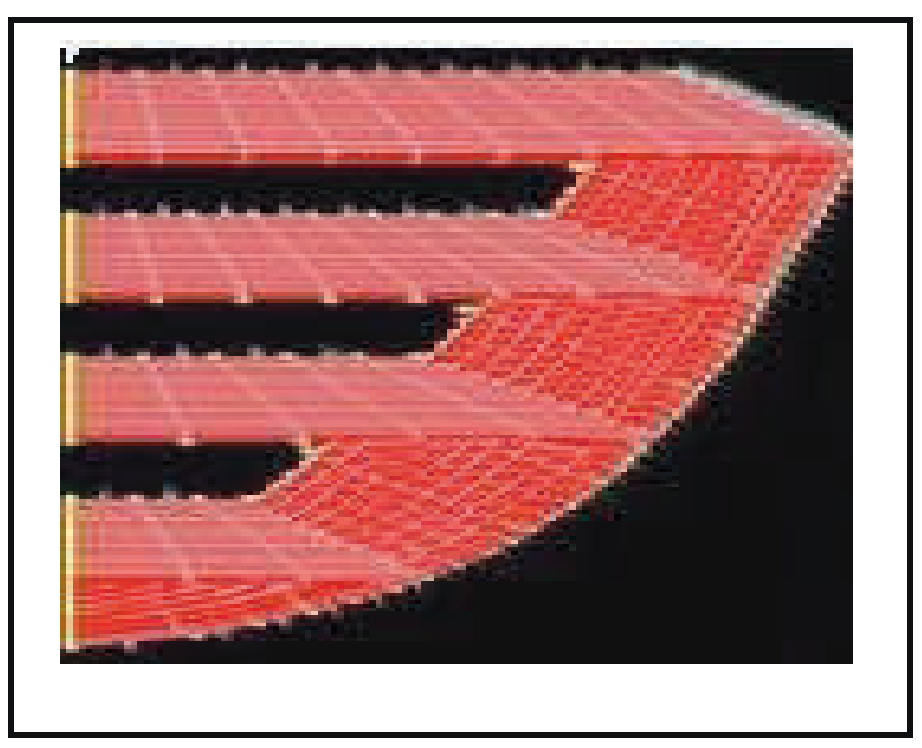

Figure 6 : Finite Element Model of Hold model 
Nonlinear analysis using geometric and combined geometric and material nonlinearities were carried out for both the models under various boundary conditions to analyze the collapse pattern and to identify the Ultimate Load Factor as the ratio of the collapse load to the design load. Three boundary conditions viz fixed, simply supported and clamped were considered at the two boundary bulkheads. Clamped is the same as the fixed case except that the longitudinal translations are permitted. Symmetric boundary conditions were applied along the centre line plane. The load displacement $(\mathrm{P}-\Delta)$ curves indicating the Ultimate Load Factor is placed at Fig 6 and 7.

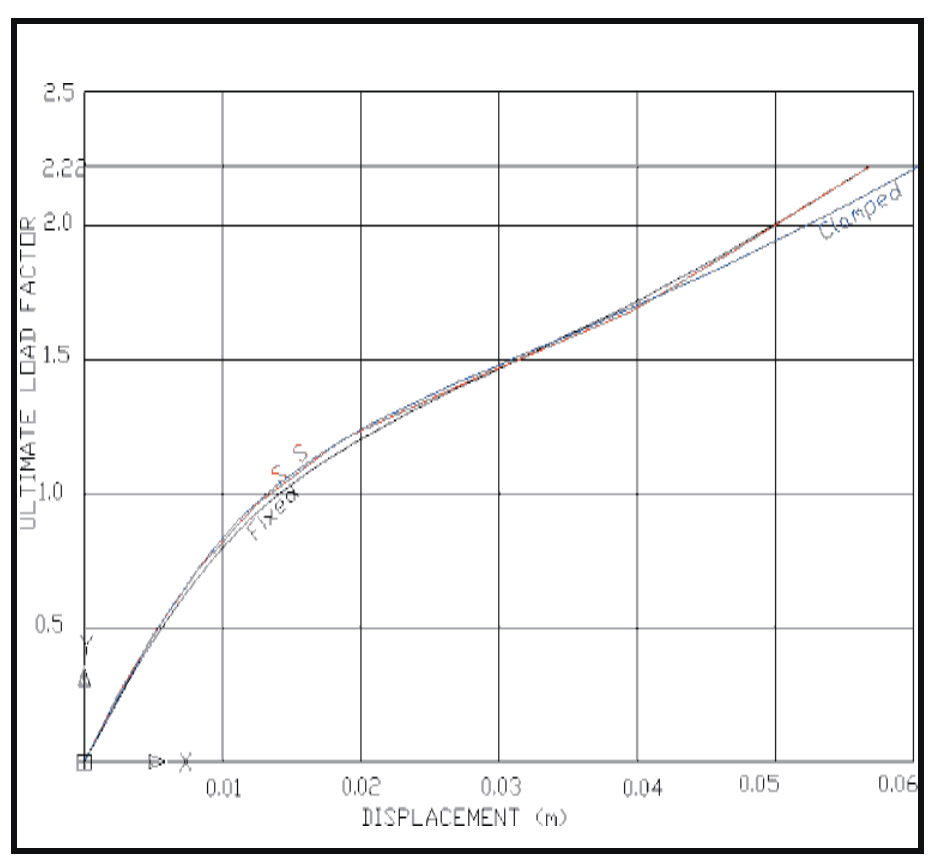

Figure 7: P- $\Delta$ Curve for Geometric Nonlinearities

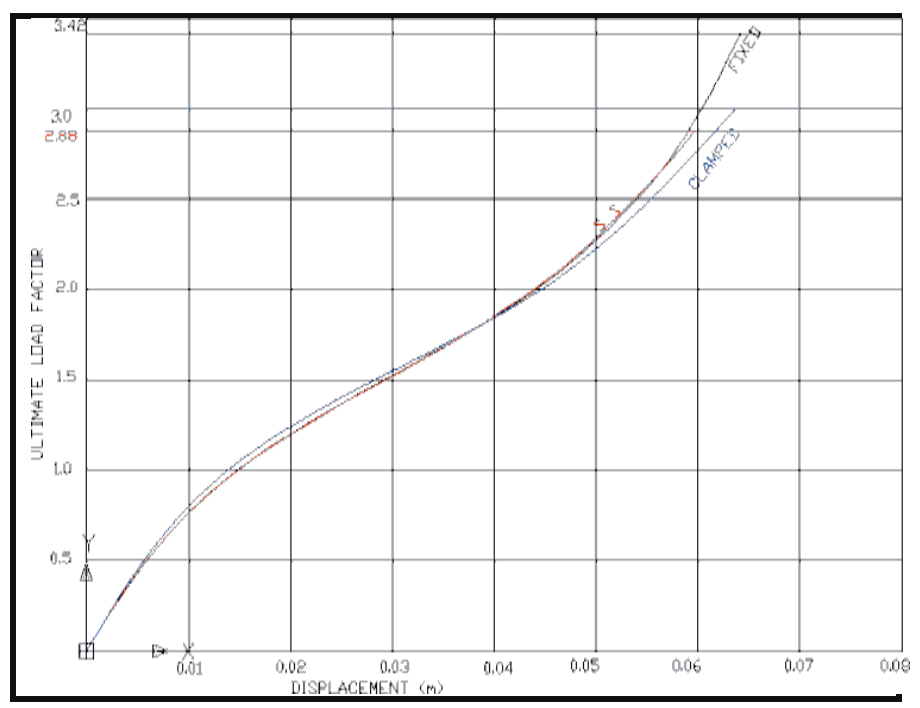

Figure 8: P- $\Delta$ Curve for Combined Nonlinearities

\subsection{Reliability Analysis based on Ultimate Limit} State Analysis.

For structural reliability prediction, factors like Young's Modulus, the shell thickness, yield stress, Poison's ratio etc., can be varied randomly. The reliability factor can be calculated based on ultimate strength load factor predicted using the finite element analysis and the probability of failure can be found by using standard statistical methods.

\section{Conclusion}

Ultimate Limit State analysis of the hold model based on the ultimate load factor predicted by both geometric and combined geometric and material nonlinearities have been conducted. Two structural configurations have been identified for ultimate strength analysis (hold and frame).

The results clearly indicate that the ultimate load factor of frame model showed considerable deviation from that of the hold model in combined nonlinear cases. Hence the frame model is not recommended for nonlinear analysis. In aviation and space industries, crash testing, full scale fatigue testing etc. are needed before safety approval is given, especially for new aircraft types.

However, in shipping industry, due to the very large size, and the lack of standardization of ship types, it is difficult to undertake full scale trials/testing to measure the actual values of stresses and loads, acceleration, forces, etc., in real-life harsh conditions for strength assessment. The potential for estimating the strength of ship structures using software based on FEM has been fully exploited in the study in assessing the ultimate strength of ships.

\section{Acknowledgments}

The author would like to express his sincere gratitude to Mr. Sunil Kumar of Aries International Maritime Research Institute for detailed comments and suggestions, which helped very much to improve the presentation of the paper. 


\section{References}

\section{Books}

[1] Basu RI, Kirkhope KJ, Srinivasan J 1996 'Guidelines for Evaluation of Ship Structural Finite Element Analysis', SSC Report 387

[2] Chalmers DW 1993 'Design of Ships' Structures', Her Majesty's Stationery Office, UK

[3] Daidola JC and Basar NS 1981 'Probabilistic Structural Analysis of Ship Hull

[4] Hughes OF 1995 'Ship Structural Design - A Rationally Based, Computer-Aided, Optimization Approach', John Wiley and Sons

[5] ISO Report ISO/CD 18072-2 2005 'Requirements for Ship structures Ultimate Limit State Assessment'

[6] Mansour AE, Thayamballi A 1980 'Ultimate Strength of a Ship's Hull Girder in Plastic and Buckling Modes', SSC Report 299 Proceedings Papers:

[7] Paik J K, Branner K, Choo YS, Czujko J, Fujikubo M, Gordo JM, Parmentier G, Iaccarino R, O'Neil S, Pasqualino I, Wang D, Wang X, Zhang S, 'Special Task Committee Report on Ultimate Strength', 17th International Ship and Offshore Structures Congress, August 2009

[8] Paik J K, Kim B J, Seo J K, Park J H, 'Ultimate Limit State Assessment of Ships and Ship Shaped Offshore Installations', 5th International Conference on High Performance Marine Vehicles, 8-10 November, 2006,Australia

[9] Yao T, Brunner E, Cho SR, Choo YS, Czujko J, Estefen SF, Gordo JM, Hess PE, Naar h, Pu Y, Rigo P, Wan ZQ, 'Special Task Committee Report on Ultimate Strength, 16th International Ship and Offshore Structures Congress', August 2006

Longitudinal Strength' - SSC Report

[10] Frick W, Bronsart R Proceedings of the 18th International Ships and Offshore Structures Congress 2012, Committee III.1 (Vol 1).

\section{Journal Papers}

[11] Assakkaf IA. and Ayyub BM (2004) 'Comparative and Uncertainty Assessment of Design Criteria for Stiffened Panels, Journal of Ship Research', Vol. 48, No. 3

[12] Leheta HW and Mansour AE (1997) 'Reliability-based Method for Optimal Structural Design of Stiffened Panels', Marine Structures 10

[13] Mansour A E, Wirsching PH, Lucket MD, Plumpton AM and Lin YH (1997) 'Structural Safety of Ships' ,SNAME Transactions Vol. 105, 1997, pp. 61-98

\section{Thesis}

[14] Sunil Kumar PG 2008 'Finite Element Analysis of Warship Structures' PhD Thesis, Cochin University of Science and Technology. 